\title{
VALORES HEMATOLÓGICOS DE CAPIVARAS (HYDROCHOERUS HYDROCHAERIS) CRIADAS EM CATIVEIRO NO MUNICÍPIO DE BOTUCATU, SP
}

\author{
HEMATOLOGICAL VALUES OF CAPTIVE CAPYBARA (HYDROCHOERUS HYDROCHAERIS) \\ IN BOTUCATU COUNTY, SÃO PAULO, SP, BRAZIL
}

\author{
Maid Eliane Arouca ${ }^{1}$ Luciana Batalha de Miranda ${ }^{2}$ Raimundo Sousa Lopes $^{3}$ \\ Regina Kiomi Takahira ${ }^{4}$ Aguemi Kohayagawa $^{5}$ Paulo César Ciarlini $^{6}$ \\ Eunice Oba ${ }^{7}$.
}

RESUMO

\begin{abstract}
Utilizaram-se onze capivaras (Hydrochoerus hydrochaeris), cinco machos e seis fêmeas, sadias, com dois anos de idade, criadas em regime de cativeiro na Fazenda Experimental Lageado da FMVZ - UNESP de Botucatu - SP. submetidas à anestesia dissociativa com midazolam e quetamina, para o estabelecimento de valores hematológicos. Este estudo compreendeu a determinação dos valores normais de eritrograma, leucograma, proteína plasmática total $e$ fibrinogênio. Os valores médios encontrados para machos e

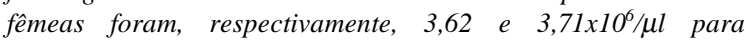
eritrócitos, 15,0 e 15,4g/dl para hemoglobina, 48 e 49\% para volume globular, 4630 e 5200/ $\mu$ l para leucócitos, 6,3 e 6,4g/dl para proteína plasmática total e 240 e 316,6mg/dl para fibrinogênio. Observou-se, desse modo, a ausência de diferenças entre os sexos.
\end{abstract}

Palavras-chave: hemograma, proteína plasmática total, fibrinogênio, capivara.

SUMMARY

Eleven healthy capybara (Hydrochoerus hydrochaeris) from the Experimental Farm Lageado - FMVZ UNESP - Botucatu, SP - Brazil, were used in order to determine the hematological values, under Midazolan and Ketamine anesthesia. This study included the determination of normal eritrogram, leucogram, total plasmatic protein and fibrinogen values. The mean values for males and females were red cell 3.62 and $3.71 \times 10^{6} / \mu l$, hemoglobin 15.0 and $15.4 \mathrm{~g} / \mathrm{dl}$, PCV 48 and $49 \%$, white cell 4630 and $5200 / \mu l$, total plasmatic protein 6.3 and $6.4 \mathrm{mg} / \mathrm{dl}$ and fibrinogen 240 and $316.6 \mathrm{mg} / \mathrm{dl}$, respectively. Diference among sex was not found.

Key words: hemogram, total plasmatic protein, fibrinogen, capybara.

\section{INTRODUÇÃO}

A capivara, o maior roedor do mundo, é um animal típico da América Latina. Em vida livre, encontra-se normalmente nas regiões mais quentes. Atualmente, a criação de capivaras em cativeiro vem crescendo muito no Brasil, pois a sua carne possui alto teor de proteínas e a sua capacidade reprodutora é maior que a bovina. A pele desse roedor é bem cotada no mercado internacional, devido à elasticidade, resistência e suavidade, sendo ótima para a fabricação de luvas, bolsas e mocassins. A gordura também pode ser utilizada na indústria farmacêutica (SILVA, 1986).

Com o interesse comercial em obter uma fonte protéica de forma rápida e com baixo custo, cresce também a necessidade de manter a sanidade desses animais. O presente estudo teve por objetivo

\footnotetext{
${ }^{1}$ Médico Veterinário, Residente, Laboratório Clínico Veterinário, Faculdade de Med. Veterinária e Zootecnia (FMVZ), UNESP de Botucatu, SP. R. Vilhena de Moraes, 100, B1. 3, apto 1001. Barra da Tijuca, 22793-140, Rio de Janeiro, RJ. Autor para correspondência.

${ }^{2}$ Médico Veterinário, Pós-graduando, Departamento de Reprodução Animal, FMVZ, UNESP, Botucatu, SP.

${ }^{3}$ Médico Veterinário, Professor Assistente Doutor, Departamento de Clínica Veterinária, FMVZ, UNESP, Botucatu, SP.

${ }^{4}$ Médico Veterinário, Professor Assistente, Departamento de Clínica Veterinária, FMVZ, UNESP, Botucatu, SP.

${ }^{5}$ Médico Veterinário, Professor Adjunto Doutor, Departamento de Clínica Veterinária, FMVZ, UNESP, Botucatu, SP.

${ }^{6}$ Médico Veterinário, Professor Assistente Doutor, FOA, UNESP, Araçatuba, SP.

${ }^{7}$ Médico Veterinário, Professor Titular Doutor, Departamento de Reprodução Animal, FMVZ, UNESP, Botucatu, SP.
} 
estabelecer os valores hematológicos da espécie, trazendo uma contribuição aos profissionais que dão assistência às criações de capivaras, uma vez que o hemograma é um exame laboratorial muito utilizado como auxílio diagnóstico, prognóstico e na avaliação dos procedimentos terapêuticos.

Com o intuito de evitar o estresse e facilitar a colheita de sangue, foi necessária a realização da anestesia nos animais, optando-se pela associação de quetamina e midazolam. A quetamina é um agente anestésico dissociativo, de ultra curta duração e, quando utilizada isoladamente pode produzir efeitos indesejáveis, devido a sua ação no sistema extrapiramidal. Por isso, procurou-se abolir ou minimizar as manifestações clínicas provocadas pela quetamina, usando-se sua associação com midazolam, um derivado benzodiazepínico (MARQUES \& MASSONE, 1988).

O eritrócito da capivara destaca-se pelo seu grande tamanho, tendo um diâmetro que varia de 8,5 a $9,0 \mu$, semelhante ao do elefante, que possui um

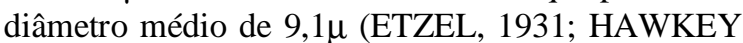
\& DENNET, 1989). Corpúsculos de Howell-Jolly podem estar presentes, embora em pequeno número (HAWKEY \& DENNET, 1989).

$\mathrm{Na}$ capivara, como em outros roedores também classificados na subordem histricomorfos (porco da índia, cuíca, etc), os leucócitos apresentam morfologia peculiar. $\mathrm{O}$ núcleo do neutrófilo apresenta lóbulos distintos e o citoplasma contêm grânulos eosinofílicos bem marcantes, semelhantes àqueles encontrados nos neutrófilos dos coelhos, o que leva à denominação de "pseudoeosinófilos". O tamanho e a distribuição dos grânulos dos pseudoeosinófilos permitem a diferenciação destes com os verdadeiros eosinófilos (ARCHER \& JEFFCOTT, 1977; JAIN, 1993; HAWKEY \& DENNET, 1989). Assim, os neutrófilos apresentam grânulos acidofílicos redondos, em menor quantidade e distribuição esparsa no citoplasma, ao passo que os eosinófilos apresentam o citoplasma totalmente ocupado por granulações maiores, em maior quantidade e intensamente acidofílicas. (ARCHER \& JEFFCOTT, 1977; JAIN, 1986; LOPES et al. 1988). O basófilo, o monócito e o linfócito da capivara assemelham-se aos das demais espécies, podendo-se observar eventualmente nos linfócitos, como em outros roedores, inclusões citoplasmáticas conhecidas como Corpúsculo de Kurloff (ETZEL, 1931; JAIN, 1986; HAWKEY \& DENNET, 1989).

\section{MATERIAL E MÉTODOS}

Foram utilizadas onze capivaras, seis fêmeas e cinco machos, com idade aproximada de 2 anos, criadas na Fazenda Experimental Lageado da Faculdade de Medicina Veterinária e Zootecnia (FMVZ) da Universidade Estadual Paulista (UNESP) de Botucatu - São Paulo. Os animais eram mantidos em regime de cativeiro, com parte coberta para abrigo, lago e árvores; diariamente, forneciamse capim Napier e milho. Após a anestesia dos animais com a associação de quetamina $(15 \mathrm{mg} / \mathrm{kg})$ e midazolam $(0,2 \mathrm{mg} / \mathrm{dl})$, colheram-se $5 \mathrm{ml}$ de sangue da veia cefálica com tubo de colheita a vácuo, contendo anticoagulante EDTA (sal dissódico do ácido etileno diamino tetracético) a $10 \%$.

Os números de eritrócitos e de leucócitos foram obtidos mediante a contagem manual em câmara de Neubauer, conforme recomendações de JAIN (1986). A concentração de hemoglobina (Hb) foi determinada pelo método de cianometahemoglobina em hemoglobinômetro ${ }^{\mathrm{a}}$ da CELM. A determinação do volume globular (VG) foi feita pelo método do microhematócrito ${ }^{\mathrm{b}}$. O mesmo tubo capilar foi utilizado para a determinação da proteina plasmática total (PPT), realizada por meio do método de refratometria e o fibrinogênio (FP) foi obtido utilizando o método de precipitação pelo calor segundo JAIN (1986).

Os cálculos dos índices hematimétricos, volume corpuscular médio (VCM), hemoglobina corpuscular média (HCM) e a concentração de hemoglobina corpuscular média (CHCM) foram realizados conforme método de WINTROBE (LEE, 1993). A contagem diferencial de leucócitos foi realizada em esfregaços sanguíneos corados pelo método Panótico Rápido ${ }^{c}$ e examinados ao microscópio óptico, com objetiva de imersão e aumento de mil vezes.

\section{RESULTADOS E DISCUSSÃO}

Os valores individuais de eritrograma, proteína plasmática total e fibrinogênio, de machos e fêmeas, estão apresentados respectivamente nas tabelas 1 e 2 . Verificou-se que os valores médios encontrados para o número de eritrócitos, volume globular, concentração de hemoglobina, VCM, HCM, CHCM e PPT mostraram-se semelhantes quando comparados machos e fêmeas; entretanto, a média de fibrinogênio foi superior nas fêmeas. Esse fato se deve a uma única fêmea que apresentou o fibrinogênio de $600 \mathrm{mg} / \mathrm{dl}$, elevando o valor da média para esse grupo, entretanto, as medianas dos dois grupos mostraram-se semelhantes.

Os valores médios encontrados para o número de eritrócitos, de machos e fêmeas, foram inferiores aos valores encontrados por ETZEL (1931) e HAWKEY \& DENNET (1989), e seme- 
Tabela 1 - Valores individuais de eritrograma, proteína plasmática total e fibrinogênio de capivaras (Hydrochoerus hydrochaeris), machos (M), criadas em regime de cativeiro em Botucatu - São Paulo.

\begin{tabular}{|c|c|c|c|c|c|c|c|c|}
\hline Animal & $\begin{array}{l}\text { Eritrócitos } \\
\left.\text { (x } 10^{6} / \mu \mathrm{l}\right)\end{array}$ & $\begin{array}{l}\mathrm{Hb} \\
(\mathrm{g} / \mathrm{dl})\end{array}$ & $\begin{array}{l}\text { VG } \\
(\%)\end{array}$ & $\begin{array}{l}\text { VCM } \\
\text { (fl) }\end{array}$ & $\begin{array}{l}\mathrm{HCM} \\
(\mathrm{pg})\end{array}$ & $\begin{array}{l}\text { CHCM } \\
(\%)\end{array}$ & $\begin{array}{l}\text { PPT } \\
\text { g/dl }\end{array}$ & $\begin{array}{l}\text { FP } \\
\mathrm{mg} / \mathrm{dl}\end{array}$ \\
\hline M1 & 4,08 & 15,6 & 51 & 125,0 & 38,2 & 30,6 & 6,3 & 300 \\
\hline M2 & 3,83 & 16,2 & 54 & 140,9 & 42,2 & 30,0 & 6,8 & 200 \\
\hline M3 & 3,37 & 14,6 & 44 & 130,5 & 43,3 & 33,2 & 6,4 & 200 \\
\hline M4 & 3,36 & 13,8 & 46 & 136,9 & 41,1 & 30,0 & 6,0 & 200 \\
\hline M5 & 3,48 & 14,8 & 45 & 129,3 & 42,5 & 32,8 & 6,4 & 300 \\
\hline $\bar{X}$ & 3,62 & 15,0 & 48 & 132,5 & 41,4 & 31,3 & 6,3 & 240 \\
\hline $\mathrm{s}$ & 0,32 & 0,9 & 4,3 & 6,3 & 1,9 & 1,5 & 0,2 & 54,7 \\
\hline Md & 3,48 & 14,8 & 46 & 130,5 & 42,2 & 30,6 & 6,4 & 200 \\
\hline $\mathrm{xi}$ & 3,36 & 13,8 & 44 & 125,0 & 38,2 & 30,0 & 6,0 & 200 \\
\hline Xs & 4,08 & 16,2 & 54 & 140,9 & 43,3 & 33,2 & 6,8 & 300 \\
\hline
\end{tabular}

$\begin{array}{ll}\overline{\mathrm{X}} & \text { Média } \\ \mathrm{s} & \text { Desvio-padrão } \\ \mathrm{Md} & \text { Mediana } \\ \mathrm{xi} & \text { Limite inferior } \\ \mathrm{xs} & \text { Limite superior }\end{array}$

lhantes aos encontrados por ARCHER \& JEFFCOTT (1977) e LOPES et al. (1988), ao passo que as médias obtidas para a concentração de hemoglobina e volume globular apresentaram-se superiores às encontradas por LOPES et al. (1988) e HAWKEY \& DENNET (1989).

O VCM da capivara destacou-se em relação a outras espécies animais pelo seu valor, que foi

Tabela 2 - Valores individuais de eritrograma, proteína plasmática total e fibrinogênio de capivaras (Hydrochoerus hydrochaeris), fêmeas (F), criadas em regime de cativeiro em Botucatu - São Paulo.

\begin{tabular}{|c|c|c|c|c|c|c|c|c|}
\hline Animal & $\begin{array}{l}\text { Eritrócitos } \\
\left(\mathrm{x} 10^{6} / \mu 1\right)\end{array}$ & $\begin{array}{l}\mathrm{Hb} \\
(\mathrm{g} / \mathrm{dl})\end{array}$ & $\begin{array}{l}\mathrm{VG} \\
(\%)\end{array}$ & $\begin{array}{l}\mathrm{VCM} \\
\text { (fl) }\end{array}$ & $\begin{array}{c}\mathrm{HCM} \\
(\mathrm{pg})\end{array}$ & $\begin{array}{l}\text { CHCM } \\
(\%)\end{array}$ & $\begin{array}{l}\text { PPT } \\
\mathrm{g} / \mathrm{dl}\end{array}$ & $\begin{array}{l}\mathrm{FP} \\
\mathrm{mg} / \mathrm{dl}\end{array}$ \\
\hline $\mathrm{F} 1$ & 3,65 & 14,6 & 47 & 128,7 & 40,0 & 31,1 & 6,8 & 400 \\
\hline $\mathrm{F} 2$ & 3,54 & 14,4 & 47 & 132,7 & 40,6 & 30,6 & 6,8 & 600 \\
\hline F3 & 3,58 & 14,8 & 48 & 134,1 & 41,3 & 30,8 & 6,3 & 300 \\
\hline F4 & 4,25 & 17,2 & 53 & 124,7 & 40,5 & 32,4 & 6,4 & 200 \\
\hline F5 & 3,55 & 15,5 & 48 & 135,2 & 43,1 & 31,9 & 6,6 & 200 \\
\hline F6 & 3,74 & 15,9 & 51 & 136,3 & 42,5 & 31,2 & 5,8 & 200 \\
\hline $\bar{X}$ & 3,71 & 15,4 & 49 & 131,9 & 41,3 & 31,3 & 6,4 & 316,6 \\
\hline $\mathrm{s}$ & 0,27 & 1,0 & 2,4 & 4,4 & 1,2 & 0,6 & 0,3 & 160,2 \\
\hline $\mathrm{Md}$ & 3,61 & 15,15 & 48 & 133,4 & 40,9 & 31,1 & 6,5 & 250 \\
\hline xi & 3,54 & 14,4 & 47 & 124,7 & 40,0 & 30,6 & 5,8 & 200 \\
\hline Xs & 4,25 & 17,2 & 53 & 136,3 & 43,1 & 32,4 & 6,8 & 600 \\
\hline
\end{tabular}

$\begin{array}{ll}\bar{X} & \text { Média } \\ \text { s } & \text { Desvio-padrão } \\ \text { Md } & \text { Mediana } \\ \text { xi } & \text { Limite inferior } \\ \text { xs } & \text { Limite superior }\end{array}$

de 131,9fl para fêmeas e 132,5fl para machos. Esses valores, considerados elevados, devem-se ao grande tamanho de suas hemácias, com diâmetro que varia de 8,5 a 9,0 . As médias de VCM observadas são semelhantes à média encontrada por LOPES et al. (1988) e superiores às apresentadas por ARCHER \& JEFFCOTT (1977) e HAWKEY \& DENNET (1989). O valor médio de CHCM de 31,3\% para fêmeas e machos mostrou-se semelhante aos encontrados por LOPES et al. (1988) e HAWKEY \& DENNET (1989).

Os valores individuais de leucócitos totais, contagens diferenciais absoluta e relativa dos leucócitos de capivaras, machos e fêmeas, estão relacionados nas tabelas 3 e 4 e as fotomicrografias das células sanguiíneas da capivara estão apresentadas na figura 1 .

Dentre os leucócitos, destacou-se a presença de marcada granulação eosinofílica nos neutrófilos, ou pseudoeosinófilos, característica da espécie (ETZEL, 1931; ARCHER \& JEFFCOTT, 1977; JAIN, 1986; HAWKEY \& DENNET, 1989). Os eosinófilos apresentaram granulações intensamente acidofílicas, maiores e em maior número em relação aos neutrófilos ou pseudoeosinófilos, muitas vezes sobrepondo-se ao seu núcleo.

Foi observado, no sangue da capivara, a ocorrência de um número variável de células da série linfocítica que contêm uma simples e grande inclusão citoplasmática. Esta única inclusão é chamada de corpúsculo de Kurloff, razão pela qual alguns autores a denominam como célula de Kurloff. JOYNER (1938), utilizando uma coloração supravital, identificou esta célula contendo corpúsculo de Kurloff como sendo um linfócito. REVELL (1974) identificou a célula de Kurloff como sendo um linfócito T, devido à formação de roseta com hemácias de coelhos. LEDINGHAN (1940) propôs haver uma relação entre o número de células linfocíticas contendo corpúsculo de Kurloff e os níveis de hormônios sexuais, pois as fêmeas apresentavam maior número dessas células até os três meses de vida. No entanto, no presente estudo, não foi observada diferença numérica entre sexos em animais aos 2 anos de idade, evidenciando-se a necessidade de maiores estudos para definir a origem da célula de Kurloff.

Com relação às contagens médias totais de leucócitos, 5.200/ $\mu$ l para fêmeas e $4.630 / \mu \mathrm{l}$ para machos, pode-se obser- 
Tabela 3 - Valores individuais de leucograma de capivaras (Hydrochoerus hydrochaeris), machos (M), criadas em regime de cativeiro em Botucatu - São Paulo.

\begin{tabular}{|c|c|c|c|c|c|c|c|c|c|c|c|}
\hline \multirow[t]{3}{*}{ Animal } & \multirow{3}{*}{$\begin{array}{l}\text { Leucócitos } \\
\text { Totais/ } \mu 1\end{array}$} & \multicolumn{10}{|c|}{ Contagem Diferencial de Leucócitos } \\
\hline & & \multicolumn{2}{|c|}{ Neutrófilos } & \multicolumn{2}{|c|}{ Linfócitos } & \multicolumn{2}{|c|}{ Basófilos } & \multicolumn{2}{|c|}{ Eosinófilos } & \multicolumn{2}{|c|}{ Monócitos } \\
\hline & & $\%$ & $/ \mu 1$ & $\%$ & $/ \mu 1$ & $\%$ & $/ \mu 1$ & $\%$ & $/ \mu 1$ & $\%$ & $/ \mu 1$ \\
\hline M1 & 4.100 & 55 & 2255 & 37 & 1517 & 0 & 0 & 4 & 164 & 4 & 164 \\
\hline M2 & 7.350 & 37 & 2719,5 & 55 & 4042,5 & 0 & 0 & 3 & 220,5 & 5 & 367,5 \\
\hline M3 & 4.250 & 60 & 2550 & 28 & 1190 & 1 & 42,5 & 4 & 170 & 7 & 297,5 \\
\hline M4 & 3.100 & 43 & 1333 & 48 & 1488 & 1 & 31 & 4 & 124 & 4 & 124 \\
\hline M5 & 4.350 & 48 & 2088 & 46 & 2001 & 0 & 0 & 2 & 87 & 4 & 174 \\
\hline $\bar{X}$ & 4.630 & 48,6 & $2.189,1$ & 42,8 & $2.067,7$ & 0,4 & 14,7 & 3,4 & 153,1 & 48 & 225,4 \\
\hline $\mathrm{s}$ & 1.600 & 9,18 & 538,2 & 10,4 & $1.195,7$ & 0,5 & 20,5 & 0,8 & 50,4 & 1,3 & 102,5 \\
\hline $\mathrm{Md}$ & 4.250 & 48 & 2.255 & 46 & 1.517 & 0 & 0 & 4 & 164 & 4 & 174 \\
\hline $\mathrm{xi}$ & 3.100 & 37 & 1.333 & 28 & 1.190 & 0 & 0 & 2 & 87 & 4 & 124 \\
\hline Xs & 7.350 & 60 & $2.719,5$ & 55 & $4.142,5$ & 1 & 42,5 & 4 & 220 & 7 & 367,5 \\
\hline
\end{tabular}

$\overline{\mathrm{X}} \quad$ Média

s Desvio-padrão

Md Mediana

xi Limite inferior

xs Limite superior

var um número discretamente maior nas fêmeas em relação aos machos. Analisando esses dados observou-se que as médias estão abaixo das encontradas por LOPES et al. (1988) e HAWKEY \& DENNET (1989).

No que se refere à contagem diferencial de leucócitos, pode-se observar o predomínio de neutrófilos (ou pseudoeosinófilos) e linfócitos, sen-

Tabela 4 - Valores individuais de leucograma de capivaras (Hydrochoerus hydrochaeris), fêmeas (F), criadas em regime de cativeiro em Botucatu - São Paulo.

$\begin{array}{ll}\text { Animal } & \begin{array}{l}\text { Leucócitos } \\ \text { Totais } / \mu 1\end{array} \quad \text { Contagem Diferencial de Leucócitos }\end{array}$

\begin{tabular}{|c|c|c|c|c|c|c|c|c|c|c|c|}
\hline & & \multicolumn{2}{|c|}{ Neutrófilos } & \multicolumn{2}{|c|}{ Linfócitos } & \multicolumn{2}{|c|}{ Basófilos } & \multicolumn{2}{|c|}{ Eosinófilos } & \multicolumn{2}{|c|}{ Monócitos } \\
\hline & & $\%$ & $/ \mu 1$ & $\%$ & $/ \mu 1$ & $\%$ & $/ \mu 1$ & $\%$ & $/ \mu 1$ & & $/ \mu 1$ \\
\hline $\mathrm{F} 1$ & 3.450 & 44 & 1518 & 47 & 1621 & 1 & 34 & 1 & 34 & 7 & 241 \\
\hline $\mathrm{F} 2$ & 4.050 & 44 & 1782 & 46 & 1863 & 0 & 0 & 6 & 243 & 4 & 162 \\
\hline F3 & 6.800 & 45 & 3060 & 48 & 3264 & 0 & 0 & 3 & 204 & 4 & 272 \\
\hline $\mathrm{F} 4$ & 5.800 & 36 & 2088 & 54 & 3123 & 1 & 58 & 5 & 290 & 4 & 232 \\
\hline F5 & 5.300 & 48 & 2544 & 47 & 2491 & 1 & 53 & 1 & 53 & 3 & 159 \\
\hline F6 & 5.800 & 42 & 2436 & 55 & 3190 & 0 & 0 & 2 & 116 & 1 & 58 \\
\hline$\overline{\mathrm{X}}$ & 5.200 & 43,1 & 2238,0 & 49,5 & $2.592,0$ & 0,5 & 24,25 & 3 & 156,7 & 3,8 & 187,4 \\
\hline $\mathrm{s}$ & 1.238 & 4,0 & 558,0 & 3,9 & 717,5 & 0,5 & 27,6 & 2,0 & 104,6 & 1,9 & 77,8 \\
\hline Md & 5.550 & 44 & 2.262 & 47,5 & 2.807 & 0,5 & 17,25 & 2,5 & 160 & 4 & 197 \\
\hline $\mathrm{xi}$ & 3.450 & 36 & 1.518 & 46 & 1.621 & 0,0 & 0,0 & 1 & 34 & 1 & 58 \\
\hline Xs & 6.800 & 48 & 3.060 & 55 & 3.264 & 1,0 & 58 & 6 & 290 & 7 & 272 \\
\hline
\end{tabular}

$\begin{array}{ll}\bar{X} & \text { Média } \\ \mathrm{s} & \text { Desvio-padrão } \\ \mathrm{Md} & \text { Mediana } \\ \mathrm{xi} & \text { Limite inferior } \\ \mathrm{Xs} & \text { Limite superior }\end{array}$

do que nos machos houve uma maior porcentagem de neutrófilos em relação aos linfócitos, e nas fêmeas inversamente, os linfócitos encontravam-se discretamente mais elevados em relação aos neutrófilos. As médias dos números de neutrófilos foram inferiores às descritas por HAWKEY \& DENNET (1989) e semelhantes àquelas evidenciadas por LOPES et al. (1988). Os valores médios dos linfócitos foram inferiores aos observados por LOPES et al. (1988) e HAWKEY \& DENNET (1989). Os valores médios encontrados para os números de basófilos e de eosinófilos foram inferiores aos citados por LOPES et al. (1988), enquanto os dos monócitos foram semelhantes aos referidos por esses mesmos autores.

As diferenças entre os resultados deste trabalho e aqueles observados na literatura compilada, provavelmente se devem às condições climáticas, manejo e sistema de alimentação a que eram submetidos os animais avaliados neste estudo.

\section{CONCLUSÃO}

Com base nos resultados obtidos e nas condições em que o trabalho foi executado, pode-se concluir que não houve diferenças de valores hematológicos determinadas pelo sexo. Os tipos leucocitários predominantes foram linfócitos e neutrófilos. Verificou-se a necessidade de maiores estudos para definir a origem do corpúsculo de Kurloff existente em alguns linfócitos.

A administração de quetamina e midazolam foi importante para promover sedação do 
animal, permitindo uma colheita de sangue tranqüila, evitando assim os efeitos indesejáveis da contenção física.

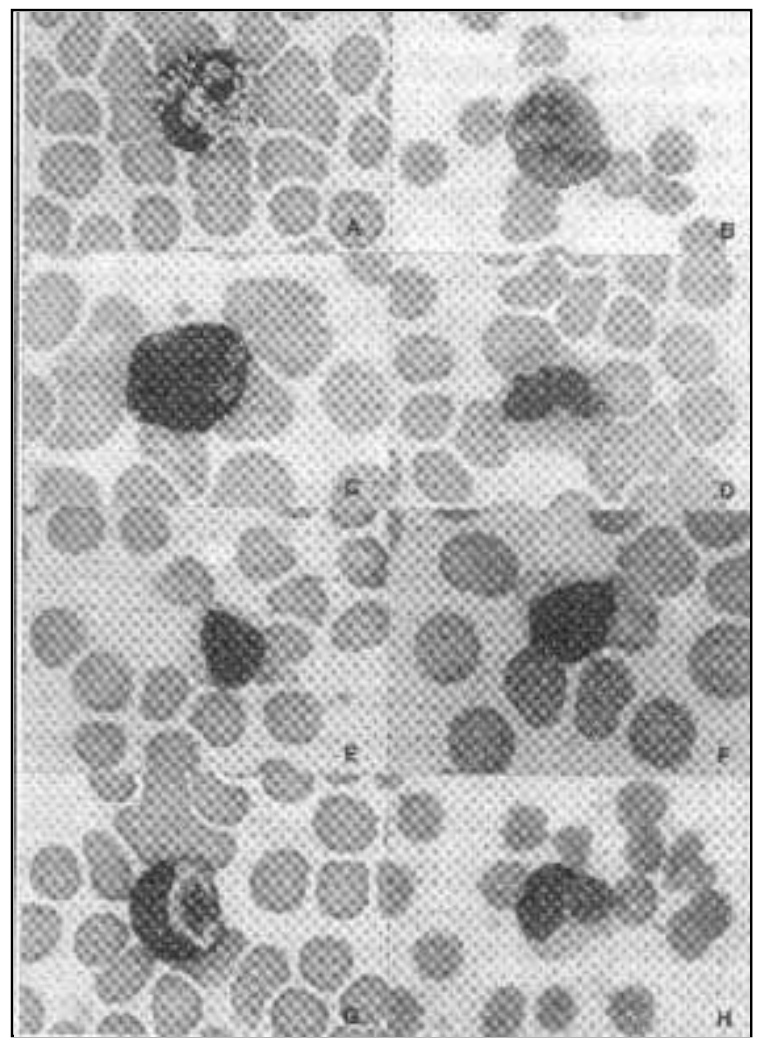

Figura 1 - Células sangüíneas da capivara (Hydrochoerus hydrochaeris). A, neutrófilo ou pseudófilo; $\mathrm{B}$, eosinófilo; C, basófilo; D, monócito; E, linfócito; F, linfócito com grânulos azurófilos; G e H, linfócitos com corpúsculo de Kurloff.

\section{FONTES DE AQUISIÇÃO}

a - Hemoglobinômetro CELM Hb 520. CELM - CIA Equipadora de Laboratórios Modernos. Rua Barata Ribeiro, 369, São Paulo - SP. b - Centrífuga para microhematócrito - CELM. CELM - CIA Equipadora de Laboratórios Modernos. Rua Barata Ribeiro, 369, São Paulo - SP.

c - Corante Panótico Rápido. Biológica Comercial LDTA. Rua Icanhema, 345/349, São Paulo - SP.

\section{REFERÊNCIAS BIBLIOGRÁFICAS}

ARCHER, R.K., JEFFCOTT, L.B. Comparative clinical haematology. Austrália : Blackwell Scientific Publications, 1977. $737 \mathrm{p}$.

ETZEL, E. Morfologia dos elementos do sangue circulante dos cavídeos silvestres. São Paulo, SP. 79p. Tese (Doutorado em Histologia e Embriologia) - Faculdade de Medicina de São Paulo, 1931.

HAWKEY, C.M., DENNET, T.B. Comparative veterinary haematology. Ipswich : W.S. Cowell, 1989. 192p.

JAIN, C.N. Essentials of veterinary hematology. Philadelphia : Lea \& Febiger, 1993. 417p.

JAIN, N.C. Shalm's veterinary hematology. 4 ed. Philadelphia: Lea \& Febiger, 1986. 1221p.

JOYNER, A.L.A study of the white blood cells of the normal Guinea-Pig. Amer J Anat, v.62, p.497, 1938.

LEE, G.R. et al. Wintrobe clinical hematology. 9 ed. Philadelphia : Lea \& Febiger, 1993. 2324p.

LEDINGHAM, J.C.G. Sex hormones and Foa-Kurloff cell. J Path Bact, v.50, p.201, 1940.

LOPES, R. S., SILVEIRA, J.M., CASTRO, K.G. et al. Valores sangüíneos de capivaras (Hydrochoerus hydrochaeris) criadas em semi-cativeiro no Mato Grosso do Sul. Revista Brasileira de Medicina Veterinária, v.10, nะ1, p.6-8, 1988.

MARQUES, J.A., MASSONE, F. Estudo das alterações cardiopulmonares e hematológicas em eqüinos pré-medicados com flunitrazepam e levopromazina e anestesiados pela cetamina. ARS Veterinária, Jaboticabal, v.4, n.2, p.185-195, 1988.

REVELL, P.A. Kurloff cell levels in the peripheral blood of normal and oestrogen treated guinea-pigs. The British Journal of Experimental Pathology, v.55, n.5, p.525-532, 1974.

SILVA, L.F.W. Criação de capivaras em cativeiro. São Paulo: Nobel, 1986. 69p.

Ciência Rural, v. 30, n. 5, 2000. 